\title{
The Revelation of the Regional Regeneration Model of International City to the Reconstruction of Taiyuan Street in Shenyang Old City
}

\author{
Qian Song ${ }^{1,}$ a , Kim cheol Soo ${ }^{2}$ \\ 1. Marine Convergence Design, Pukyong National University, Busan, Korea \\ 2.Dept. of Industrial Design Pukyong National University, Busan, Korea \\ a467226543@qq.com
}

Keywords: Urban Renewal; Public Art; Culture Inheritance; Visual Design.

\begin{abstract}
Objective Through the study of urban regeneration model, it provides the enlightenment value for the regeneration of Taiyuan Street in Shenyang old city. Method In this paper, the success of the regeneration model is analyzed, and the successful regeneration mode is discussed in this paper. Conclusion According to the policy of the city's double repair, the urban regeneration model is one of the best ways to solve the urban innovation and continuation. Urban regeneration for the local residents, to improve the living environment to improve life satisfaction; for the city itself, to improve the image of the city and comprehensive competitiveness, resulting in higher added value; for social resources, to better the continuation of history, heritage culture. Reasonable urban regeneration model can promote a region of sustainable development and innovation, and design is the most simple and effective way of urban regeneration.
\end{abstract}

\section{Introduction}

2016 China central city work conference proposed "double major city" policy and clearly the dual cultivation of each work mission, city double refers to through ecological restoration, improving urban environment and repaired by city, improve the urban landscape. Namely, control environmental pollution, restore the natural ecology, and puts forward the orderly implementation of urban repair and organic renewal, solve the old city environment quality decline, space order, the problem such as damage to historical and cultural heritage, promote buildings, streets, facade, skyline, colour and environment more coordinate and beautiful [1]. Urban regeneration refers to the adjustment and improvement of old urban areas on the basis of the original historical features of the city, so as to improve the vitality and environmental quality of the old city. From the concept of urban renewal, urban regeneration is one of the many means of urban construction, which is most in line with the requirement of "urban double repair" policy. This paper discusses the cultural regeneration in urban regeneration -- from the perspective of visual arts, it discusses the visual repair of urban features and the regenerative mode of historical and cultural continuity.

\section{Urban Space Landscape Regeneration}

in the $90 \mathrm{~s}$, the industrial age has changed the production structure of the society as a whole, has provided people with convenient modern mechanical design, but also changed the traditional mode of handicraft industry, the natural ecology and the sustainable development of human beings in crisis. Urban development is also so, China's urban construction has experienced "urban renewal - urban new city", has the Chinese characteristic architectural element, cultural element, cultural element is shrinking as the construction of the new town. Urban regeneration is one of the development of the urban renewal strategy, mainly from the material space, and so on various aspects of economy and society, for bearing the weight of the old town, old town of city historical memory improvement and renovation to repair type, government-led, residents participation, change the region face to attract private investment, a virtuous circle eventually make urban functions, urban landscape visual formation. City regeneration's purpose is to protect and continue urban historical context, including 
the physical space in building urban regeneration of regeneration and repair of urban heritage, for the history of old style and the historical environment to create a new order relation, "in the old with the new", "fusion of old and new" to create each culture characteristic of the urban space landscape [2]. Urban regeneration including historical style and features and the regeneration of urban culture, and history view and the regeneration of urban culture is the most direct embodiment of the city's physical space, physical space view of urban regeneration not only has important significance but also has important significance for the city itself. Such as the Prague, capital of the Czech Republic, because of the history of the city landscape has been complete protection so the city was identified as the world cultural heritage, the tourism industry alone each year have brought huge economic income. With our neighbors South Korea and Japan although there is no complete like Prague has kept the city landscape of city, but the existing old city regeneration, also have brought high international reputation, for example Osaka, Japan, South Korea Busan. And visual art design is the most visual appeal and urban space landscape regeneration performance tension of a "technique", the urban construction of the facade wall is the most easy to come into contact with the people in the city space landscape, "representation" used properly can increase people's impression of urban landscape, if improper performance is easy to make the wall ignored, so this article is aimed at urban space landscape building facade wall of visual design methods in research.

\section{Case Analysis}

three old town in Shenyang Taiyuan street is located in Kaifeng street, lane, north of the north road, south of four with jersey north street, west of area of about 2500 square meters. The block is a after one hundred years of commercial block, since 1898 to loan, the block remains in most of the building is the building during the period of the republic of China, for residential, today is still a small number of people living here, but most of the building has long been abandoned, severely damaged facade, public infrastructure, old and poor street environment. The region, which has a complete history of urban and historic houses, is a part of Shenyang city memory. Shanghai Xintiandi is on loan in the 19th century, Busan GanChuan village tai chi is 50 years of the 19th century believers and "6 · 25" war refugees of living space, similar to Shenyang old town, these two areas are made by foreign researchers gathered to form the physical space, and Shanghai Xintiandi and GanChuan village through successful "regeneration" is recognized in the world, new world has become the international life entertainment plaza, Santorini GanChuan village into South Korea. Therefore, this chapter analyses the regeneration mode and technique of the successful building facade of these two regions.

\subsection{Urban Regeneration of Shanghai Xintiandi}

Shanghai Xintiandi is located in the central district of Shanghai huaihai road south huangpi road in the east, south near the Zhong road, west near the horse when road, taicang road in the north, center a societe generable road divides into the square in the south and north. Xintiandi has a history of more than a century. It is a place where the building of shikumen with Shanghai characteristics is gathered, which is concentrated in the history and culture of Shanghai and the lifestyle of residents in Shanghai [3]. From the perspective of preserving the historical landscape, Shanghai Xintiandi is a successful one, which successfully protected and recreated the style of shikumen in the regeneration of the facade of the building facade. The regeneration method is divided into two kinds: 1 . New and new world architecture based on the characteristics of old buildings.

There are two kinds of old buildings: 1 . Complete preservation of the old buildings, and repair and maintain them. A big site, such as, the communist party of China building facade for water brick wall, brick wall color is divided into green red, cyan is adornment as the main body, red, red decoration pattern for transverse linear decoration pattern, this kind of decorative pattern. The only difference is the vertical height of different; The gate is the traditional Chinese lacquer door, but the arch of the door is embossed in the style of the baroque scroll. The complete re-enactments of the construction products of this particular period of shikumen, the complete facade of the building provides tourists with Shanghai in the 1920s and 1930s. 2. The same as old buildings, these buildings have been worn out or damaged because of historical reasons but are still building facade and historical data can fully 
recover its original shape, so it to its original shape-based replication to repair, looks like the old building is a new building. For example, the repair of ARK music, the material of the building facade, the area of each material, the paving technique of the wall, and the style of the Windows and doors are all synchronized and restored.

"Old and new combined with" new building a new world, the most primitive function is residential, "renewable" and gives it more space function of the business, shopping and travel, in order to meet the new functions cater to modern people's psychological, this place is beyond repair and not old buildings of historical value "new", this kind of building facade regeneration technique is divided into two kinds: 1. The old and new contrast of new modern buildings, such as, new world fashion shopping center, this is a new shopping center, in order to highlight the traditional architecture of massiness, and does not destroy, and disrupted the traditional architectural visual order, the use of large area glass facade, glass is a typical modern materials and its visual sense both thin and soft, both to the era of contrasts and water brick wall, without Xuan Bing away; 2. New and old fusion of new buildings, on the basis of the old buildings, add new architectural language to details. For example, the main building of the small square surrounding the main interruption, the walls still use the original old walls, but the Windows on the second floor are enlarged and changed to a new type of large glass wall; The facade of the front door of Le Club also USES the same regeneration method -the glass form on the second floor. Luna restaurants are used to increase glass facade regeneration method, but the difference is increase Luna restaurant is the entire glass facade, with brick wall facade and glass facade out an inner courtyard, let old wall direct "dialogue".

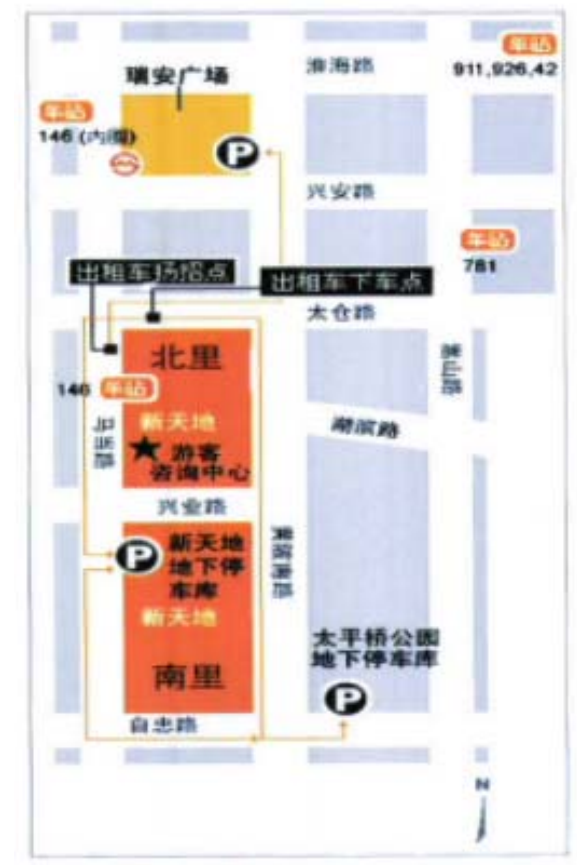

Figure 1. Xintiandi plan

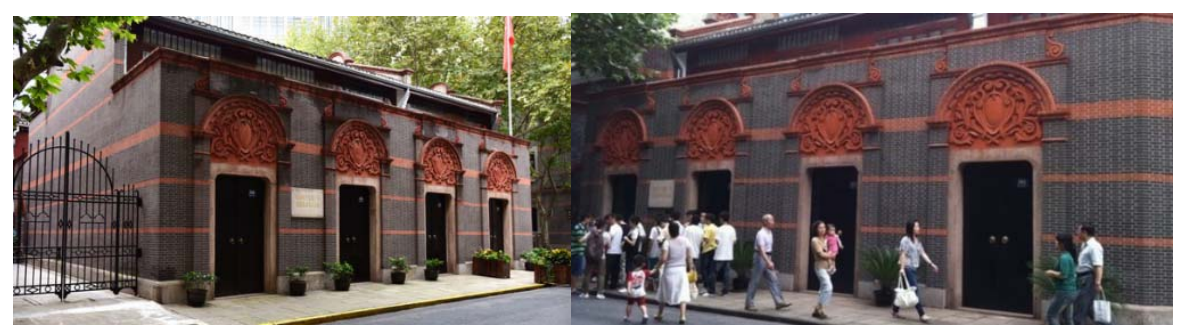




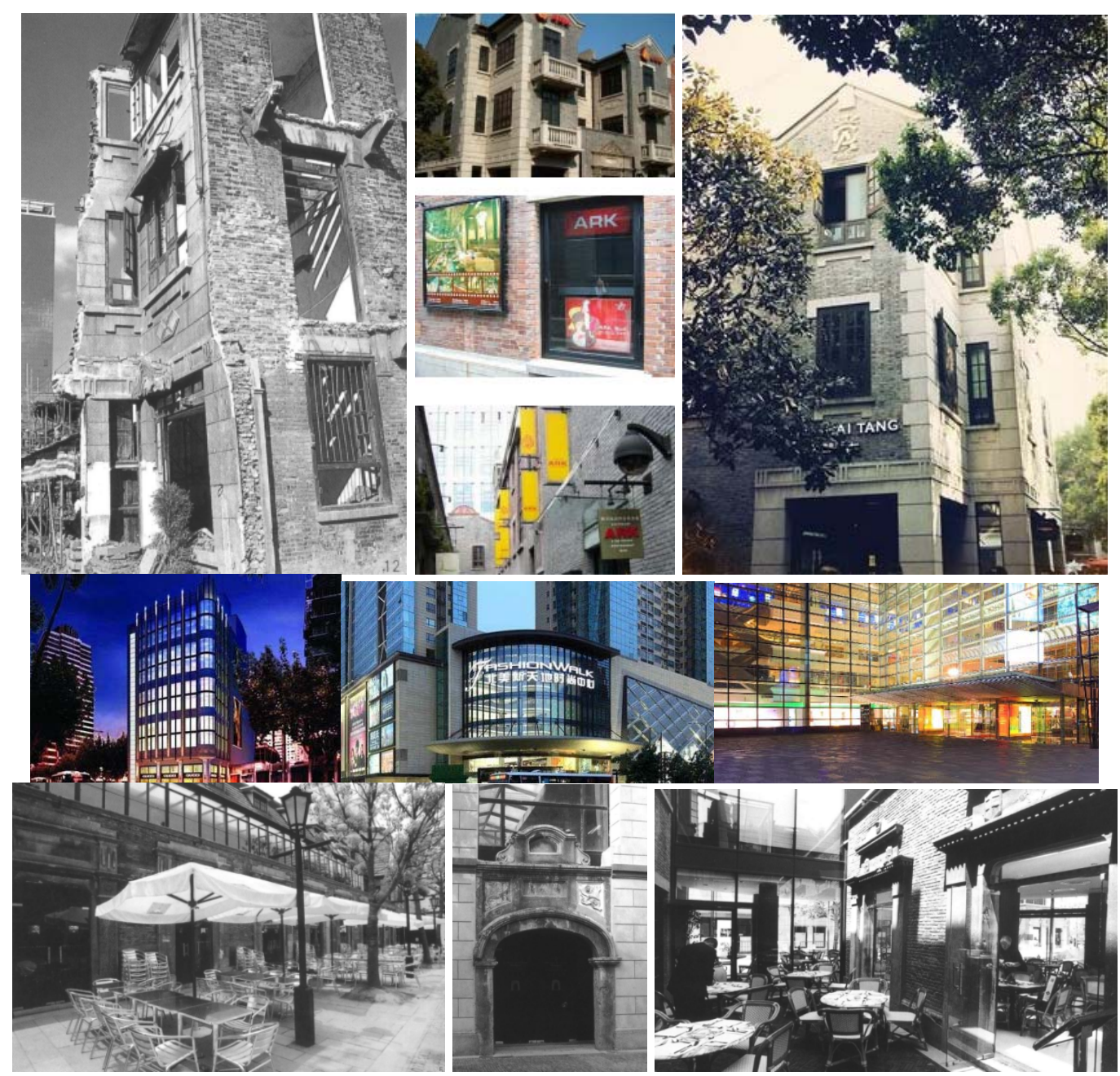

Figure 2. Shanghai Xintiandi

\subsection{Urban Regeneration of Ganchuan Culture Village -- Public Art Strategy}

Busan GanChuan village tai chi is 50 years of the 19th century believers and "6 $\cdot 25$ " war refugees of living space, because of its historical background so here in the refugee camp of city development situation is not optimistic. South Korea in the $1990 \mathrm{~s}$ to the national large-scale urban regeneration [4], GanChuan village is under the background of this era for the development of the regenerative, GanChuan village of regeneration and began in 2009 to 2014 the basic forming [5]. GanChuan village of regeneration is through public art in the form of a renewable, change the look of the local environment become tourism, increase the income of the local residents, to Busan local many liberal artists provide employment.

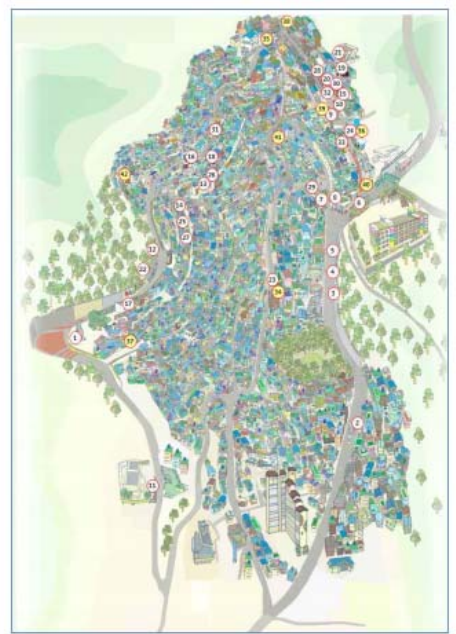

Figure 3. Busan Gamcheon Culture Village plan 
The public art strategy is mainly reflected in the regeneration of the facade of ganchuan building. The interactive strategy of man and facade. Building facade landscape regeneration methods are divided into four kinds: 1 . The color elevation: South Korea local-style dwelling houses are finishing with different colour (the south Korean government about the structure of the colour has specific rules, parts finishing colors are derived from rules of color number), each house will have their own uniform color, red yellow and green all sorts of color photograph echo increases the local space of the beautiful; 2. Hand-painted wall mural: GanChuan village in the process of development of cultural regeneration, invited well-known artists, art lovers, Pusan art teachers and students, etc., various colleges and universities to participate the wall murals, draw on the wall in the form of hand-painted murals of various styles; 3. In addition to color and hand-painted pictures, the muscular reason decoration will be used to construct different facade effects, such as wood engraving and porcelain; 4 . The combination of "micro landscape", the three decorative means mentioned in the front, any combination of any combination of plants or sculptures to create a small landscape facade.
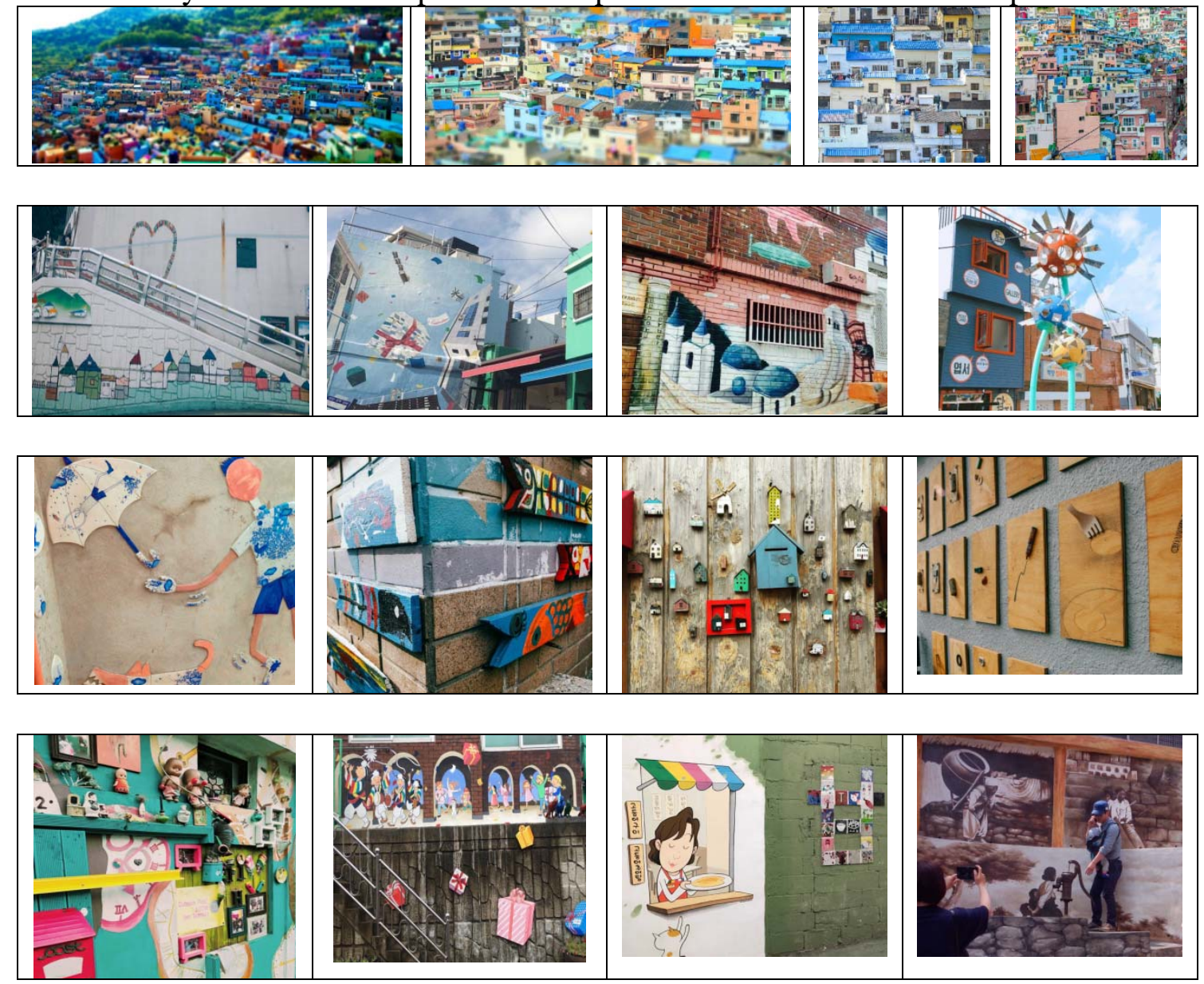

Figure 4. Busan Gamcheon Culture Village

The interaction between people and facade walls can be divided into three categories: visual interaction, behavioral interaction and emotional interaction. At the same time, in fact, the three kinds of interaction are existing, only to see different elevation after produce the different proportion of three kinds of interaction, this leads to the interactive rhythm of the human and space changes, frequent interaction can give a person travel burden - visual exhaustion, exhaustion of body and so on, so in the space of building facade design, to be in a different way to create different forms of interaction. The four kinds of details mentioned above can bring visual interaction to people. Interaction, by three methods of 2, 3, 4, is mainly refers to people will touch facade or and facade took photo, as the chart of hand-painted wall murals, $3 \mathrm{~d}$ wall murals will bring people full of interesting "optical illusion", or $2 \mathrm{~d}$ hand-painted wall again, only draw the part of the design, and design can be merged into a complete picture, and so on, this kind of facade can stimulate people's interaction; Emotional interaction is the sublimation of visual and behavioral interaction, while the visual and 
interactive behavior will bring emotional but this kind of emotional interaction are indirect, in the GanChuan village is the most direct emotional interaction through a high degree of recognition of classic cartoon characters to convey (e.g., the little prince), through these classic image closer to the distance between people and the environment, increase intimacy and human and environment friendly feeling.

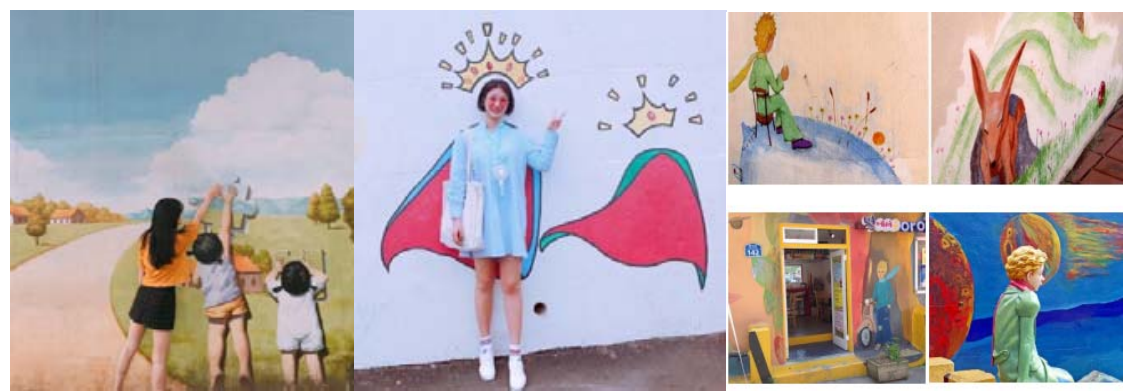

Figure 5. Busan Gamcheon Culture Village

\section{Inspiration for the Regeneration of Taiyuan Street in the Old City of Shenyang}

The regeneration of Xintiandi is the co-existence of recovery and innovation. The highlight is "old and new dialogue". The regeneration of ganchuan culture village is creative regeneration, and the highlight is the investment of public art. Two regions of similar historical origin have achieved the success of regeneration through different regeneration methods, providing practical experience for the regeneration of Taiyuan street in the old city of Shenyang. 1. To protect the original space, local correction and detail maintenance as best as possible; 2 . The need for large-scale repair or damaged seriously the facade of regeneration, can be divided into two kinds, one kind is carried out in accordance with the original style and recovery, in the regeneration process must pay attention to details, such as for the recovery of shikumen in Xintiandi, from material to the structure, including detail pattern to do height reduction; The other is the innovative recovery, the extraction of the original space or the characteristic elements of the building to inject new ideas, such facade style as "the old saying" general. The combination of old and new, innovative style and regeneration method inside a lot of, can draw lessons from the "percentage" law of Xintiandi, the facade one hundred percent of the area as a unit, water brick, shikumen for glass Windows for the modern design elements of traditional symbols, signs, according to the whole area to differentiate the proportional relationship between them, a new facade wall for notoginseng ratio and more than; 3 . A new facade style design, such designs are divided into two kinds, one kind is similar to a new fashion of this kind of new building construction, the facade style to choose visual effect on the processing of soft materials, such as glass. The facades of the second kind is GanChuan village landscape regeneration, increase space through the investment of public art culture value, this paper discusses on the specific details of the design techniques have been, but it is important to note that in the regeneration of public art in the following two points: first of all, be sure to choose the color of the coordinated with the original space view, can take pictures and professional color measurement instrument (Spector photo - metercm - 700 - d) to collect the color of the traditional block, and by far the most commonly used spectra magic nx ver. 2.03 software of color quantitative analysis, and then with the help of Munsell color system or the PCCS - tone color system, lists needed in the design of the color; Second, must pay attention to the interactive section gather together, GanChuan village interactive section gather together just a little too often, almost all of the walls are painted murals, so that visitors are often when they leave a slip of the tongue calls it the "painting village", so in the process of the whole facade landscape planning to plan out key interactive facade, other facade to the relative weakening of the interaction effect of, such both neither can cause visual burden to people and can reduce the distance of people and the environment. 


\section{Conclusion}

The urban construction decades ago ignored the main body of the city due to its historical limitations, and the inheritance and protection of culture. Urban regeneration ignored before the point in the face, but in the process of regeneration area according to the actual situation, can't take, not just the facade style regeneration, public facilities, ground shop, etc., want to consider every detail, by way of the design on the protection of traditional culture of the city and region, design aesthetic and practical value, with the minimum investment in order to win the greatest social benefits.

\section{References}

[1]. Ministry of Housing and Urban-Rural Development: city renewal and construction Dec. 12th 2012

[2]. http://finance.ifeng.com/a/20161212/15072399_0.shtml

[3]. Jianguo Wang <City transition and renewal $>$

[4]. Jiru Ye. Shanghai Xintiandi architecture and environmental analysis. [J].57-59

[5]. Hanbin Han. < Analysis of the evolution of "residents participating in urban regeneration" in Seoul, South Korea>[J]. 2016(08):141-147; 